\title{
Quantitative Monitoring of the Volatiles from the Aerial Parts of Satureja hortensis by the use of HS-SPME-GC-MS Approach
}

\author{
MAJID MOHAMMADHOSSEINI ${ }^{\star 1}$, PARVANEH REZAEI ${ }^{2}$, \\ ABOLFAZL AKBARZADEH ${ }^{3}$ and MARYAM BEIRANVAND 1
}

'Department of Chemistry, Shahrood Branch, Islamic Azad University, Shahrood, Iran. 2Department of Chemistry, Tonekabon Branch, Islamic Azad University, Tonekabon, Iran.

${ }^{3}$ Drug Applied Research Center, Tabriz University of Medical Sciences, Tabriz, Iran.

${ }^{*}$ Corresponding author E-mails: m_mhosseini@iau-shahrood.ac.ir

http://dx.doi.org/10.13005/ojc/320527

(Received: June 15, 2016; Accepted: August 13, 2016)

\begin{abstract}
The volatile fractions isolated from the ground aerial parts of Satureja hortensis were trapped using the headspace solid phase microextraction (HS-SPME) strategy and subsequently monitored using gas chromatography in combination with mass spectrometry (GC-MS) instrumentation. Eleven constituents were totally recognized in the analyzed volatile parts, representing entire of the corresponding profile. Among the natural groups present in the chemical profile, monoterpene hydrocarbons $(99.5 \%)$ were found as the major constituents with the dominant compounds being $\gamma$-terpinene (46.0\%), $p$-cymene (11.8\%), $\alpha$-terpinene (11.1\%), $\alpha$-pinene $(10.4 \%)$ and $\alpha$-thujene $(6.8 \%)$. However, lower contents of some natural compounds including myrcene $(5.2 \%), \beta$-pinene $(3.9 \%)$, o-cymene $(2.6 \%), \alpha$-phellandrene $(1.1 \%)$, camphene $(0.6 \%)$ and thymol $(0.5 \%)$ were identified. Accordingly, only $0.5 \%$ of the profile included oxygenated monoterpenes.
\end{abstract}

Keywords: Satureja hortensis, volatile compounds, $\gamma$-terpinene, p-cymene, $\alpha$-terpinene, GC/MS, monoterpene hydrocarbons.

\section{INTRODUCTION}

In the plant sciences, the Lamiaceae family has been known in detail of which many species can produce adequate essential oils having versatile pharmaceutical characteristics. In the literature, it has been pointed out that the Satureja genus involves twelve species with promising phytochemical and medicinal properties. The endemic species of this genus in Iran include $S$. atropatana, S. bachtiarica S. edmondi, S. intermedia, S. isophylla, S. kallarica, S. khuzistanica and $S$. sahendica. It should be also noted that the other famous species of the Satureja, namely $S$. boissieri, S. macrantha, S. mutica and $S$. 
spicigera are mainly found in some parts of Iraq, Turkey, Ghafghaz (Northern and Southern regions) as well as Turkmenistan ${ }^{1}$.

In the Iranian traditional and folk medicine, Satureja hortensis L. which is called as Marzeh is widely used as an effective remedy to treat some disorders and malfunctions of digestions in the human body. The extracts of this herbal plant serve as potent sedative agents and can also relief cramps or address nausea along with diarrhea. Moreover, in the cookery this plant is frequently used as a flavoring agent ${ }^{2}$.

From morphological point of view, its average height falls within the $10-35 \mathrm{~cm}$ range. The flowers of $S$. hortensis appear in white or lilac colors. This valuable plant could be found in different situations including wet, dried and moderate climatic conditions ${ }^{3}$.

A brief literature survey reveals that some species of the Satureja genus could be considered as proper medical remedies in view of their potential anti-inflammatory ${ }^{4-6}$, antioxidant ${ }^{7-10}$, antinociceptive ${ }^{4,}$ 5 , antimicrobial ${ }^{9-15}$, antigenotoxic ${ }^{16}$, antispasmodic and anti-diarrheal ${ }^{17}$, anti-fungal ${ }^{18}$, insecticidal ${ }^{19,20}$ and antibacterial ${ }^{11}$ activities.

The relaxant effect of an aqueous-methanol extract of $S$. hortensis has been tested on guinea pig trachea ${ }^{21}$. According to the findings of this report, $S$. hortensis serves as an excellent relaxant and its influence is comparable with that of theophylline. In addition, according to some of the previous studies, this plant is a rich source of some useful phenolic, antioxidant and flavonoids ${ }^{22-24}$. Furthermore, an important oxygenated monoterpene, namely thymol has been measured in the extracts of $S$. hortensis by using the HPTLC technique ${ }^{25}$.

Regarding a broad spectrum of phytochemical activities related to the different members of the Satureja genus, it is so rational to characterize the composition of the secondary metabolites or volatiles and separate bioactive compounds in each profile.

Over the recent decades, the combination of headspace analysis with solid phase microextraction standpoint, namely abbreviated as HS-SPME has gained a unique interest in different fields of analytical sciences. The HS-SPME technique is inherently free of solvent and can be directly used to analyze diverse matrices like plants, foods, fragrances and biological samples ${ }^{26-33}$. In a very recently report, we have described the potential capability of this technique using the least amounts of plant samples when using four types of organic fibers ${ }^{34}$.

In the present report, we intend to describe the results of quantitative and qualitative analyses of the volatiles obtained from the aerial parts of $S$. hortensis using the HS-SPME-GC-MS approach. In the literature, some sporadic studies are found relating to the characterization of the water-distilled essential oils of this plant ${ }^{11}, 13,20,35$. However, there is no report concerning profiling of the volatiles of $S$. hortensis using the aforementioned approach in Semnan Province, Iran up to present.

\section{EXPERIMENTAL}

\section{Reagents and plant authentication}

To calculate the Kovats indexes, a complete range of normal paraffins $\left(\mathrm{C}_{9}-\mathrm{C}_{24}\right)$ were provided from Fluka Company. Additionally, all the carrier gases utilized in gas chromatographic-based separations were ultrapure. On 15 April 2015, fresh aerial parts of $S$. hortensis were sampled from a small village (Foroomad, $1230 \mathrm{msl}$ ) located at $150 \mathrm{~km}$ far from Shahrood. According to our global positioning system (GPS), the geographic coordinates of the sampling area were found to be north latitude $36^{\circ} .30^{\prime}$ and east longitude $56^{\circ} .45^{\prime}$. Moreover, to authenticate the botanical name of the plant sample, a voucher specimen has been deposited at a reliable herbarium belonging to Research Institute of Forests and Rangelands (RIFR), Tehran, Iran.

\section{General characteristic of the proposed HS-SPME approach}

To trap the volatiles from the aerial parts of $S$. hortensis, a complete SPME set-up was provided from Supelco, Bellefonte, USA. This assembly involves a miniaturized microtubing which its surface has been coated with a proper organic polymer namely PDMS-CAR. To perform the respective analysis, as it is customary in such sorts of studies, the fiber should be initially conditioned 
at a temperature of $250^{\circ} \mathrm{C}$ for about 30 minutes in the injector of the GC-MS apparatus. Immediately after, minimal amounts of the dried and powdered plant sample (about $1.0 \mathrm{~g}$ ) in the especial vials were situated under a temperature of $70^{\circ} \mathrm{C}$ for about fifteen minutes. This results in the release of volatile fractions from the plant material. After piercing the septum by the needle of the SPME, its fiber was allowed to stand in the headspace medium formed above the sample vials. In the next step, the fiber retracted to the needle and the needle was directly placed in the injection port of the GC-MS instrument. Finally, the temperature was regulated at $250^{\circ} \mathrm{C}$ when the injection port was set at the splitless mode for about five minutes.

\section{Chemical profile identification}

The main patterns to finalize identification of the chemical profile related to the volatile fractions from the aerial parts of $S$. hortensis using the HS-
SPME-GC-MS technique were as follows.

1. Matching of numerical Kovats indices with those tabulated in the standard references $^{36-39}$,

2. Consistency of mass spectral fragmentation with reliable references,

3. The resemblance reports given by the library of the GC-MS apparatus (>90\%),

4. Regarding the findings of our previous reports 27-30, 33, 40-71.

\section{GC and GC-MS quantifications}

Both gas chromatography (GC, Shimadzu 15A: FID detector) and gas chromatography-mass spectrometry (GC-MS, Hewlett-Packard 5973) determinations were performed under the identical temperature programmings. However, the column types in these techniques were respectively a DB-5 with general dimensions of $50 \mathrm{~m} \times 0.2 \mathrm{~mm}$, film thickness $0.32 \mu \mathrm{m}$ as well as an HP-5MS

Table 1: Volatile composition from the aerial parts of S. hortensis obtained by using the HS-SPME-GC-MS method ${ }^{a}$

\begin{tabular}{|c|c|c|c|c|c|c|}
\hline No. & Compound & Class & $R_{t}^{d}$ & RI (Lit.) ${ }^{\mathrm{e}}$ & RI (Cal.) ${ }^{f}$ & Percentage \\
\hline 1 & $\alpha$-Thujene & $\mathrm{MH}^{\mathrm{b}}$ & 6.4 & 931 & 923.3 & 6.8 \\
\hline 2 & $\alpha$-Pinene & $\mathrm{MH}$ & 6.5 & 939 & 929.9 & 10.4 \\
\hline 3 & Camphene & $\mathrm{MH}$ & 6.8 & 953 & 945 & 0.6 \\
\hline 4 & $\beta$-Pinene & $\mathrm{MH}$ & 7.5 & 980 & 973.8 & 3.9 \\
\hline 5 & Myrcene & $\mathrm{MH}$ & 7.8 & 991 & 988.9 & 5.2 \\
\hline 6 & $\alpha$-Phellandrene & $\mathrm{MH}$ & 8.1 & 1005 & 1002.3 & 1.1 \\
\hline 7 & $\alpha$-Terpinene & $\mathrm{MH}$ & 8.4 & 1018 & 1015.2 & 11.1 \\
\hline 8 & p-Cymene & $\mathrm{MH}$ & 8.5 & 1020 & 1023.8 & 11.8 \\
\hline 9 & o-Cymene & $\mathrm{MH}$ & 8.6 & 1022 & 1027.6 & 2.6 \\
\hline 10 & $\gamma$-Terpinene & $\mathrm{MH}$ & 9.3 & 1062 & 1061.3 & 46.0 \\
\hline \multirow[t]{6}{*}{11} & Thymol & $\mathrm{OM}^{\mathrm{c}}$ & 14.1 & 1290 & 1313.2 & 0.5 \\
\hline & & $\mathrm{MH}$ & & Number & & 10 \\
\hline & & & & Percentage & & 99.5 \\
\hline & & OM & & Number & & 1 \\
\hline & & & & Percentage & & 0.5 \\
\hline & & Total & & & & 100 \\
\hline
\end{tabular}

\footnotetext{
a The compounds have been sorted according to their retention indices on an HP-5 MS capillary column

${ }^{\mathrm{b}}$ Monoterpene hydrocarbons

${ }^{c}$ Oxygenated monoterpene

${ }^{\mathrm{d}}$ Retention time (Min.)

${ }^{\text {e } K o v a t z ~ r e t e n t i o n ~ i n d i c e s ~ g i v e n ~ i n ~ t h e ~ l i t e r a t u r e ~}$

${ }^{\dagger}$ Calculated Kovatz retention indices
} 


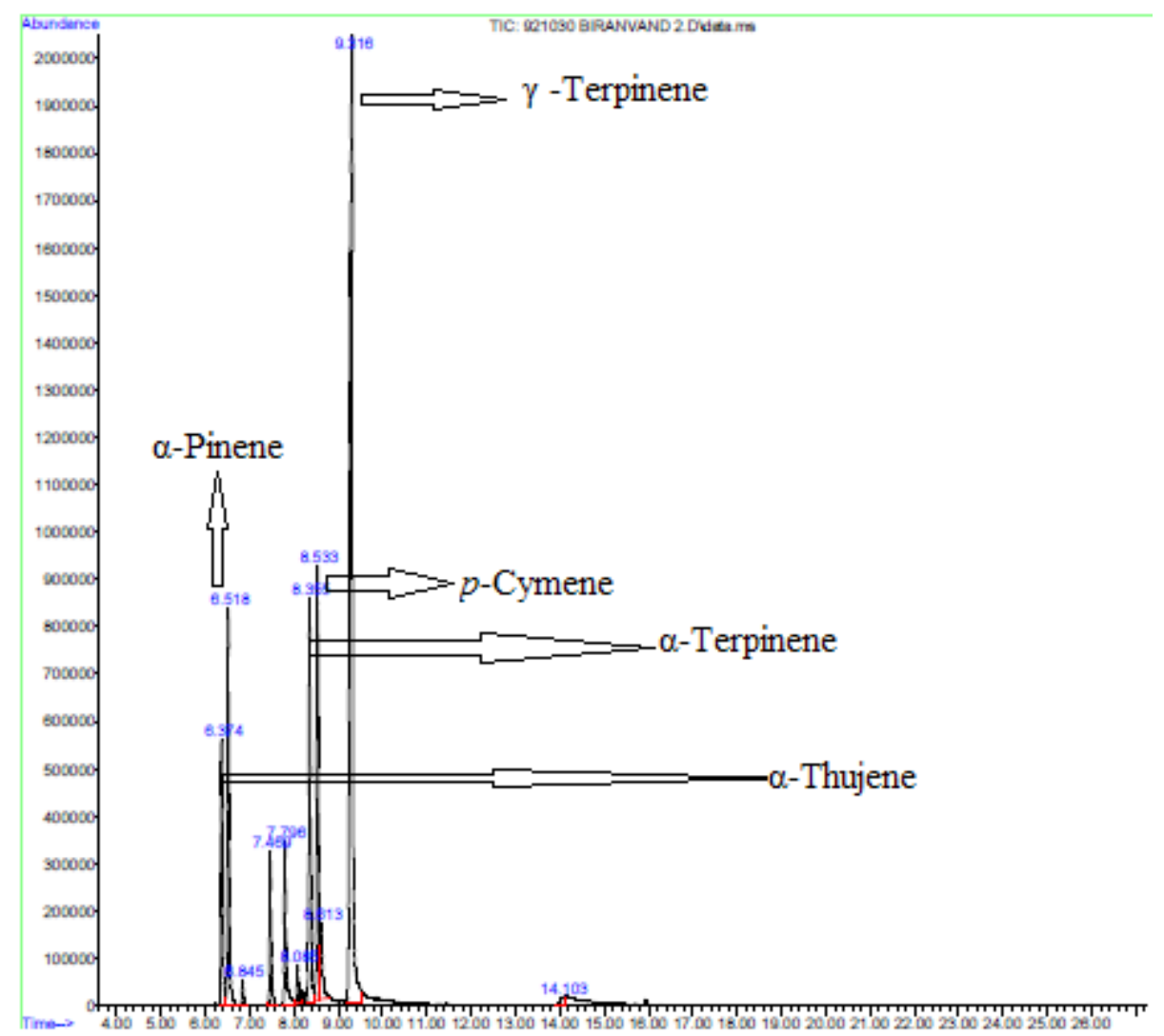

Fig. 1: GC-MS chromatogram for the volatile fraction from the aerial parts of $S$. hortensis

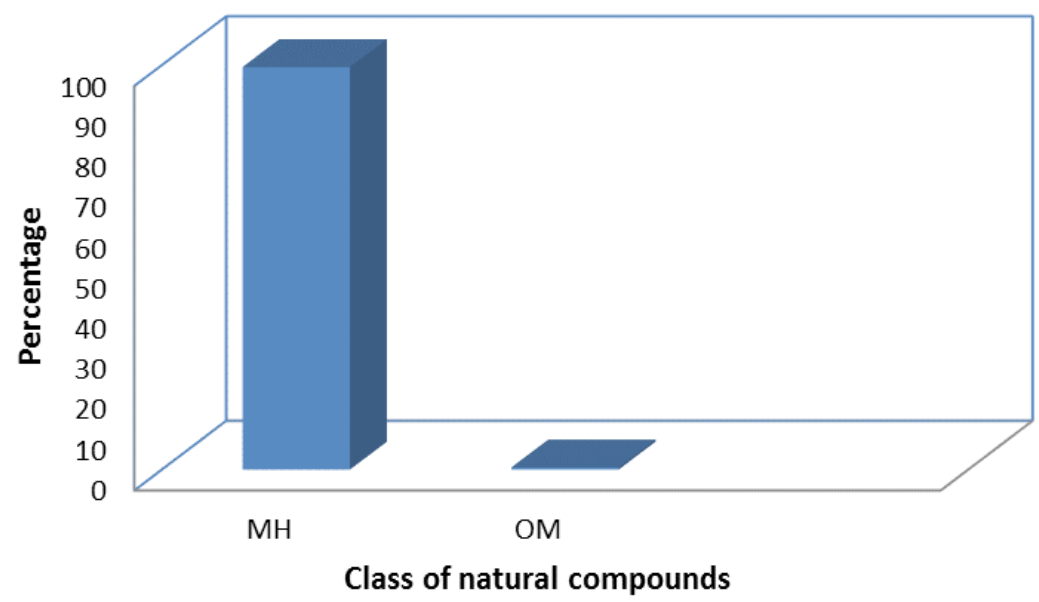

Fig. 2: Percentages of the classes of natural compounds found in the volatiles from aerial parts of $S$. hortensis using the HS-SPME-GC-MS method ( $\mathrm{MH}=$ monoterpene hydrocarbon; $\mathrm{OM}=$ oxygenated monoterpene) 
column having $50 \mathrm{~m} \times 0.2 \mathrm{~mm}$, film thickness $0.32 \mu \mathrm{m}$. In all of our determinations, the temperature of each column was first set at the temperature of $60^{\circ} \mathrm{C}$ for three minutes and then gradually increased to a final temperature of $230^{\circ} \mathrm{C}$ by applying a rate of $5^{\circ} \mathrm{C} / \mathrm{min}$. The carrier gases used in the GC and GC-MS approaches were respectively nitrogen and helium all having a flow-rate of $1.0 \mathrm{ml} / \mathrm{min}$. The ionization energy in the GC-MS instrumentation was $70 \mathrm{eV}$ within the mass range of 30-350 amu.

\section{RESULTS AND DISCUSSION}

\section{Composition of the $\boldsymbol{S}$. hortensis volatile profile}

Characterization of the chemical compositions of the essential oils separated from $S$. hortensis has been reported in some of the previous studies in the literature ${ }^{12,13,72}$. However, regardless of some similarities, we identified a rather new profile relating to the volatiles from the aerial parts of this species. According to our identification, totally eleven compounds contributed to the volatile profile of this plant. The names, groups, retention times, retention indexes (calculated and literature tabulated) have been shown in Table 1. The closeness between the Kovats values confirms the authenticity of the profile identification.

Screening of the general composition of the volatiles from the aerial parts of $S$. hortensis resulted in recognition of ten monoterpene hydrocarbons $(\mathrm{MH})$ together with one oxygenated monoterpene (OM) respectively accounting for $99.5 \%$ and $0.5 \%$ of the total profile (see Table 1 and Figure 1). In this regard, $\gamma$-terpinene $(46.0 \%)$, $p$-cymene (11.8\%), $\alpha$-terpinene (11.1\%), $\alpha$-pinene $(10.4 \%), \alpha$-thujene $(6.8 \%)$ and myrcene $(5.2 \%)$ were found as the most abundant constituents of the profile. Furthermore, $\beta$-pinene $(3.9 \%)$, o-cymene (2.6\%), $\alpha$-phellandrene (1.1\%), camphene $(0.6 \%)$ and thymol $(0.5 \%)$ were detected among the other components contributing to the profile.

Meanwhile, the schematic representation of the natural compound groups in this profile has been represented in Figure 2. As can be seen, most of the chemical composition from the volatiles of $S$. hortensis consists of monoterpene hydrocarbons.

\section{Comparison of the chemical profiles of $S$.} hortensis oils

According to the literature, profiling of the chemical compositions of the water-distilled essential oils from different parts of $S$. hortensis has been the subjects of some earlier works. In the work of Adiguzel and coworkers, the major constituent of $S$. hortensis oil (dried fruits) has been reported as thymol $(40.54 \%)$ followed by terpinene $(18.56 \%)$, carvacrol $(13.98 \%)$ and $p$-cymene $(8.97 \%)^{3}$. Baser et al..$^{72}$ have also reported components of the essential oils of twenty wild and cultivated samples in different regions of Turkey. In accordance with this study, in all of the cultivated profiles carvacrol was identified as the main constituent, whereas another oxygenated monoterpene, namely thymol constituted most of the essential oils from the wild samples profiles ${ }^{72}$. It should be also mentioned that carvacrol has been identified as the main constituent component in a variety of similar works being focused on the compositions of the essential oils of Satureja species ${ }^{11,13,20,35,74-76}$.

Khajeh et al have identified high quantities of $\gamma$-terpinene, thymol and carvacrol in the hydrodistilled essential oil and SFE-extracts $\left(\mathrm{CO}_{2}\right.$ fluid) of $\mathrm{S}$. hortensis ${ }^{73}$. The quantitative and qualitative influence of growth stage on compositions of the oils of $S$. hortensis revealed dominance of $\gamma$-terpinene in all cases with the exception of ripened fruit stage involving carvacrol as the major component ${ }^{74}$. Using a combination of traditional and advanced separation techniques to isolate the essential oils from $S$. hortensis before an HPTLC analysis resulted in identifying some oxygenated monoterpenes (thymol, carvacrol, linalool, citronellol, and geraniol) together with two monoterpene hydrocarbons ( $\alpha$-pinene: mixture and limonene $)^{25}$, as well. However, the findings of the present report are similar to our recently published work ${ }^{75}$. In fact, the simple comparison shows that both profiles mainly consist of monoterpene hydrocarbons.

\section{CONCLUSION}

The main goal of this study was to establish a deeper insight into the capability of the HS-SPME technique coupled to GC-MS analysis to evaluate composition of the volatile fractions from the aerial parts of $S$. hortensis as a proper medicinal 
plant. Our study led to whole identification of the corresponding chemical profile consisting of eleven natural compounds of which ten were monoterpene hydrocarbons $(99.5 \%)$ and only one $(0.5 \%)$ was an oxygenated monoterpene. The most abundant compounds present in the volatile profile were found to be $\gamma$-terpinene $(46.0 \%)$, $p$-cymene $(11.8 \%)$, $\alpha$-terpinene (11.1\%), $\alpha$-pinene (10.4\%), $\alpha$-thujene $(6.8 \%)$ and myrcene $(5.2 \%)$ followed by $\beta$-pinene (3.9\%), o-cymene (2.6\%), $\alpha$-phellandrene $(1.1 \%)$, camphene $(0.6 \%)$ and thymol $(0.5 \%)$ with lower percentages.

\section{ACKNOWLEDGEMENTS}

The authors intend to express their immense gratitude to the Office for Research Affairs of the Islamic Azad University, Shahrood Branch for providing technical and financial supports.

\section{REFERENCES}

1. Mozaffarian, V. A Dictionary of Iranian Plant Names. Farhang Moaser Press, Tehran, Iran, 1996.

2. Zargari, A. Medicinal Plants. Tehran University Publication, Tehran, Vol. 2, 1991.

3. Adiguzel, A.; Ozer, H.; Kilic, H.; Cetin, B. Czech J. Food Sci. 2007, 25, 81-89.

4. Hajhashemi, V.; Ghannadi, A.; Pezeshkian, S. K. J. Ethnopharmacol. 2002, 82, 83-87.

5. Hajhashemi, V.; Zolfaghari, B.; Yousefi, A. Med. Princ. Pract. 2012, 21, 178-182.

6. Uslu, C.; Karasen, R. M.; Sahin, F.; Taysi, S.; Akcay, F. J. Ethnopharmacol. 2003, 88, 225228.

7. Bandoniene, D.; Venskutonis, P. R.; Gruzdiene, D.; Murkovic, M. Eur. J. Lipid Sci. Technol. 2002, 104, 286-292.

8. Dorman, H. J. D.; Hiltunen, R. Food Chem. 2004, 88, 193-199.

9. Gulluce, M.; Sokmen, M.; Daferera, D.; Agar, G.; Ozkan, H.; Kartal, N.; Polissiou, M.; Sokmen, A.; Sahin, F. J. Agric. Food. Chem. 2003, 51, 3958-3965.

10. Shojaee-Aliabadi, S.; Hosseini, H.; Mohammadifar, M. A.; Mohammadi, A.; Ghasemlou, M.; Ojagh, S. M.; Hosseini, S. M.; Khaksar, R. Int. J. Biol. Macromol. 2013, 52, 116-124.

11. Djenane, D.; Yangueela, J.; Amrouche, T.; Boubrit, S.; Boussad, N.; Roncales, P. Food Sci. Technol. Int. 2011, 17, 505-515.

12. Mihajilov-Krstev, T.; Radnovic, D.; Kitic, D.; Stojanovic-Radic, Z.; Zlatkovic, B. Biotechnol. \& Biotechnol. Eq. 2009, 23, 1492-1496.

13. Mihajilov-Krstev, T.; Radnovic, D.; Kitic, D.; Zlatkovic, B.; Ristic, M.; Brankovic, S. Cent. Eur. J. Biol. 2009, 4, 411-416.
14. Venskutonis, P. R.; Sipailiene, A.; Sarkinas, A. Composition and antimicrobial effects of savory (Satureja hortensis) essential oils isolated by different methods. In Recent Advances in Food and Flavor Chemistry: Food Flavors and Encapsulation, Health Benefits, Analytical Methods, and Molecular Biology of Functional Foods, Ho, C. T.; Mussinan, C. J.; Shahidi, F.; Contis, E. T., Eds. RSC Publishing, 356-360, 2010.

15. Sahin, F.; Karaman, I.; Gulluce, M.; Ogutcu, H.; Sengul, M.; Adiguzel, A.; Ozturk, S.; Kotan, R. J. Ethnopharmacol. 2003, 87, 61-65.

16. Behravan, J.; Mosaffaa, F.; Karimi, G.; Iranshahi, M. Planta Med. 2006, 72, 965.

17. Hajhashemi, V.; Sadraei, H.; Ghannadi, A. R.; Mohseni, M. J. Ethnopharmacol. 2000, 71, 187-192.

18. Gumus, T. Radiat. Phys. Chem. 2010, 79, 109-114.

19. Pavela, R.; Sajfrtova, M.; Sovova, H.; Barnet, M. Appl. Entomol. Zool. 2008, 43, 377-382.

20. Tozlu, E.; Cakir, A.; Kordali, S.; Tozlu, G.; Ozer, H.; Akcin, T. A. Sci. Horticult. 2011, 130, 9-17.

21. Boskabady, M.; Aslani, M.; Mansuri, F.; Amery, S. Daru 2007, 15, 199-204.

22. Plander, S.; Gontaru, L.; Blazics, B.; Veres, K.; Kery, A.; Kareth, S.; Simandi, B. Eur. J. Lipid Sci. Technol. 2012, 114, 772-779.

23. Lung, I.; Soran, M. L.; Tudoran, C.; Marutoiu, C. Cent. Eur. J. Chem. 2013, 11, 535-541.

24. Bros, I.; Soran, M. L.; Briciu, R. D.; Cobzac, S. C. J. Planar Chromatogr.-Mod. TLC 2009, 22, 25-28.

25. Soran, M. L.; Varodi, C.; Cobzac, S. C.; Lung, I. J. Essent. Oil-Bear. Plants 2011, 14, 699- 
707.

26. Ozeka, G.; Demirci, F.; Ozek, T.; Tabanca, N.; Wedge, D. E.; Khan, S. I.; Baser, K. H. C.; Duran, A.; Hamzaoglu, E. J. Chromatogr. A 2010, 1217, 741-748.

27. Akhlaghi, H.; Nekoei, M.; Mohammadhosseini, M.; Motavalizadehkakhky, A. J. Essent. OilBear. Plants 2012, 15, 328-335.

28. Mohammadhosseini, M.; Mahdavi, B.; Akhlaghi, H. J. Essent. Oil-Bear. Plants 2013, 16, 613-623.

29. Mohammadhosseini, M.; Nekoei, M.; Mashayekhi, H. A.; Aboli, J. J. Essent. OilBear. Plants 2012, 15, 506-515.

30. Nekoei, M.; Mohammadhosseini, M.; Akhlaghi, H. J. Essent. Oil-Bear. Plants 2012, 15, 926933.

31. Delgado, F. J.; Gonzalez-Crespo, J.; Cava, R.; Garcia-Parra, J.; Ramirez, R. Food Chem. 2010, 118, 182-189.

32. Huang, B.; Lei, Y.; Tang, Y.; Zhang, J.; Qin, L.; Liu, J. Food Chem. 2011, 125, 268-275.

33. Mohammadhosseini, M.; Nekoei, M. J. Essent. Oil-Bear. Plants 2014, 17, 747-757.

34. Mohammadhosseini, M. J. Essent. Oil-Bear. Plants 2015, 18, 464-476.

35. Ghannadi, A. J. Essent. Oil Res. 2002, 14, 35-36.

36. Erbil, N.; Duzguner, V.; Durmuskahya, C.; Alan, Y. Oriental J. Chem. 2015, 31, 53-58.

37. Erbil, N.; Duzguner, V.; Durmuskahya, C.; Alan, Y. Oriental J. Chem. 2015, 31, 12631268.

38. Gupta, J.; Gupta, A. Oriental J. Chem. 2015, 31, 231-235.

39. Adams, R. P. Identification of Essential Oil Components by Gas Chromatography/Mass Spectrometry. Allured Publishing Co., Carol Stream, IL., USA, 2007.

40. Mohammadhosseini, M.; Pazoki, A.; Akhlaghi, H. Chem. Nat. Comp. 2008, 44, 127-128.

41. Mohammadhosseini, M.; Zamani, H. A.; Akhlaghi, H.; Nekoei, M. J. Essent. Oil-Bear. Plants 2011, 14, 559-573.

42. Mohammadhosseini, M.; Pazoki, A.; Zamani, H. A.; Akhlaghi, H. J. Essent. Oil-Bear. Plants 2011, 14, 101-105.

43. Mohammadhosseini, M.; Pazoki, A.; Zamani, H. A.; Akhlaghi, H.; Nekoei, M. J. Essent. OilBear. Plants 2010, 13, 704-709.
44. Hashemi-Moghaddam, H.; Mohammadhosseini, M.; Salar, M. Anal. Methods 2014, 6, 2572-2579.

45. Hashemi-Moghaddam, H.; Mohammadhosseini, M.; Basiri, M. J. Essent. Oil-Bear. Plants 2015, 18, 884-893.

46. Mohammadhosseini, M. J. Essent. Oil-Bear. Plants 2015, 18, 1360-1371.

47. Mohammadhosseini, M.; Mahdavi, B.; Shahnama, M. J. Essent. Oil-Bear. Plants 2015, 18, 1321-1328.

48. Mohammadhosseini, M. A Comprehensive Review on New Methods for Processing, Separation and Identification of the Essential Oils. Islamic Azad University of Shahrood Press, Shahrood, Iran, 2016.

49. Mohammadhosseini, M.; Akbarzadeh, A.; Hashemi-Moghaddam, H.; Mohammadi Nafchi, A.; Mashayekhi, H. A.; Aryanpour, A. J. Essent. Oil-Bear. Plants 2016, 19, 32-45.

50. Nekoei, M.; Mohammadhosseini, M. J. Essent. Oil-Bear. Plants 2016, 19, 59-75.

51. Mohammadhosseini, M.; Deeb, O.; AlaviGharabagh, A.; Nekoei, M. Anal. Chem. Lett. 2012, 2, 80-102.

52. Mohammadhosseini, M. Asian J. Chem. 2012 24, 3814-3820.

53. Mohammadhosseini, M. Asian J. Chem. 2012, 24, 1432-1434.

54. Mohammadhosseini, M. Asian J. Chem. 2013, 25, 390-392.

55. Mohammadhosseini, M. Anal. Chem. Lett. 2013, 3, 226-248.

56. Mohammadhosseini, M. J. Chem. Health Risks 2014, 4, 75-95.

57. Mohammadhosseini, M.; Akbarzadeh, A.; Hashemi-Moghaddam, H.; Shahnama, M.; Fahimi, B.; Azami, S. Oriental J. Chem. 2016, 32, 1439-1451.

58. Nekoei, M.; Mohammadhosseini, M.; AlaviGharahbagh, A. J. Appl. Chem. 2009, 4, 3951.

59. Nekoei, M.; Mohammadhosseini, M. Anal. Chem. Lett. 2014, 4, 93-103.

60. Rahimi, M.; Karimi, E.; Nekoei, M.; Mohammadhosseini, M. J. Essent. Oil-Bear. Plants 2016, 19, 307-320.

61. Mohammadhosseini, M.; Akbarzadeh, A.; Shafaghat, A.; Hashemi-Moghaddam, H.; Mohammadi Nafchi, A.; Ashouri, H. J. Essent. 
Oil-Bear. Plants 2016, 4, 863-874.

62. Akhlaghi, H.; Shafaghat, A.; Salimi, F.; Mohammadhosseini, M. Anal. Chem. Lett. 2011, 1, 325-327.

63. Akhlaghi, H.; Asl, M.R. S.; Mohammadhosseini, M. Chem. Nat. Comp. 2009, 45, 448-449.

64. Akhlaghi, H.; Shafaghat, A.; Mohammadhosseini, M. J. Essent. Oil-Bear. Plants 2009, 12, 365-368.

65. Motavalizadehkakhky, A. R.; Shafaghat, A.; Zamani, H. A.; Akhlaghi, H.; Mohammadhosseini, M.; Mehrzad, J.; Ebrahimi, Z. J. Med. Plants Res. 2013, 7, 1280-1292.

66. Mohammadhosseini, M. J. Herbal Drugs 2016, 7, 97-108.

67. Mohammadhosseini, M. J. Med. Plants ByProd. 2016, In press.
68. Mohammadhosseini, M.; Akbarzadeh, A.; Hashemi-Moghaddam, H. J. Essent. Oil-Bear. Plants 2016, 19, In press.

69. Nekoei, M.; Mohammadhosseini, M. J. Essent. Oil-Bear. Plants 2016, 19 In press.

70. Pasha Zanousi, M. B.; Nekoei, M.; Mohammadhosseini, M. J. Essent. Oil-Bear. Plants 2016, 19, In press.

71. Mohammadhosseini, M.; Nekoei, M. J. Essent. Oil-Bear. Plants 2016, 19, In press.

72. Baser, K. H. C.; Ozek, T.; Kirimer, N.; Tumen, G. J. Essent. Oil Res. 2004, 16, 422-424.

73. Khajeh, M. J. Supercrit. Fluids 2011, 55, 944948.

74. Saharkhiz, M. J.; Zomorodian, K.; Rezaei, M. R.; Saadat, F.; Rahimi, M. J. Nat. Prod. Commun. 2011, 6, 1173-1178.

75. Mohammadhosseini, M.; Beiranvand, M. J. Chem. Health Risks 2013, 3, 49-60. 